\title{
Secondary Lens Implantation: Incidence, Indications and Complications
}

\author{
B. LEATHERBARROW, A. TREVETT and A. B. TULLO
}

Manchester

\begin{abstract}
Summary
A retrospective study of 79 secondary intraocular lens implants performed during 1984-87 in a large teaching hospital is reported. The period of follow-up ranged from 6 months to 3.9 years (mean 16.6 months). The principal indication for surgery was contact lens intolerance. Thirtyfour per cent of the patients had previously undergone cataract surgery with implantation of the other eye. Eighty-three per cent of the patients achieved a visual acuity within one Snellen line of best-corrected preoperative visual acuity. A further $2.5 \%$ lost two lines of Snellen chart acuity, and $14.5 \%$ had a substantial reduction in visual acuity. We conclude that in carefully selected patients secondary intraocular lens implantation is an acceptable and often highly successful way of treating monocular aphakia and we discuss the selection and preoperative investigation of such patients.
\end{abstract}

The practice of secondary intraocular lens implantation in the management of aphakia has gained widespread acceptance in the United States of America. ${ }^{(1-8)}$ It is probable that this procedure is also being carried out in many centres in this country, perhaps on an occasional basis, though no reported series have been identified in the British literature. We report here experience at the Royal Eye Hospital, Manchester, which currently accounts for a small but growing proportion of the total number of lens implants used.

\section{Patients}

Seventy-nine secondary intraocular lens implantations performed by 18 surgeons were included in this study. This involved 72 patients as 7 patients underwent bilateral secondary intraocular lens implantation. The surgery was performed in the 40 month period from February 1984 to July 1987. Excluded from the study were 15 secondary intraocular lens implantations performed within 3 weeks of failed primary implantation as this prevented accurate assessment of bestcorrected visual acuity prior to secondary implantation. All data were obtained by retrospective review of patient records. The intraocular lenses were all implanted via a corneal incision which was placed either superiorly or temporally.

The mean age of the patients was 73 years (range 15-94 years). The age categories of the patients are given in Table I. Twenty-eight patients $(39 \%)$ were male and $44(61 \%)$ were female. Fifty-two operations $(66 \%)$ were performed under general anaesthesia and 27 operations (34\%) under local anaesthesia. The average interval between the primary and secondary procedures was 5.2 years (range 3 months to 27 years). This interval was greater than one year in 71 cases $(90 \%)$. All patients have been followed-up for a minimum period of 6 months. The average length of follow-up was 16.6 months with a range of 6 to 46 months.

Correspondence to: B. Leatherbarrow Royal Eye Hospital, Oxford Road, Manchester, M13 9WL.

Presented at the Annual Congress of the Ophthalmological Society of the United Kingdom, April 1988. 
Table I Age categories of patients (years)

\begin{tabular}{ccccc}
\hline $0-20$ & $21-40$ & $41-60$ & $61-80$ & $81-100$ \\
2 & 4 & 12 & 39 & 15 \\
\hline
\end{tabular}

The indications for secondary intraocular lens implantation were contact lens intolerance in 50 cases $(63 \%)$, contact lens related problems such as a corneal ulceration and corneal vascularisation in 12 cases $(15 \%)$, aphakic intolerance in 11 cases $(14 \%)$ and failed primary implantation due to operative complications in 6 cases $(8 \%)$.

Twenty-six operations $(32 \%)$ were performed by a consultant, 43 operations $(55 \%)$ by a senior registrar, 8 operations $(10 \%)$ by a registrar and 2 operations $(3 \%)$ by a senior house officer.

The incidence of this procedure is rapidly increasing at this centre. This is illustrated in Figure 1.

Fifty-five eyes $(70 \%)$ had previously undergone an intracapsular cataract extraction. Of the remaining 24 eyes $(30 \%)$, eight had suffered a penetrating eye injury and subsequently had undergone an extracapsular cataract extraction leaving the posterior capsule intact. Five eyes had undergone a planned uncomplicated extracapsular cataract extraction. Three eyes had undergone a planned extracapsular cataract extraction during which operative problems prevented primary implantation despite an intact posterior capsule. Five eyes had undergone an extracapsular cataract extraction during which the posterior capsule had ruptured, with vitreous loss necessitating an anterior vitrectomy in three eyes. Two eyes had undergone a dicission for congenital cataract. The remaining eye had undergone a planned intracapsular extraction which was completed as an extracapsular extraction with an intact posterior capsule remaining.

Seventy-one eyes $(90 \%)$ were implanted with an anterior chamber lens. These were all flexible lenses. They consisted of 23 "Symflex" lenses, 21 "Cilco Multiflex" lenses, 20 "Novaflex" lenses, 3 "Rayner" lenses, 2 "Medical Optics" lenses, one " 3 M" lens, and one "IOLAB" lens. Seven eyes $(9 \%)$ were implanted with a posterior chamber lens. These consisted of five
No. of cases

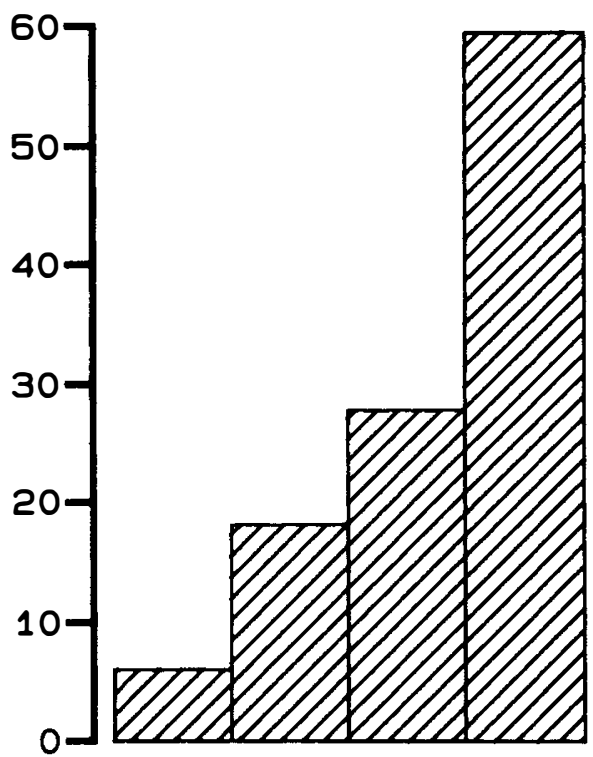

1984198519861987

Fig. 1. Incidence of secondary implantation at Manchester Royal Eye Hospital 1984-87. Al cases in each year included

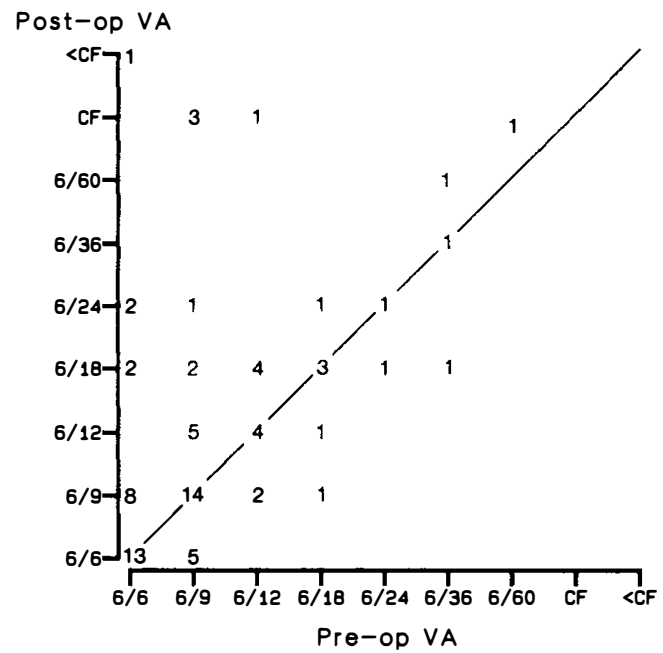

Fig. 2. Scatter diagram relating preoperative and postoperative visual acuities in eyes that underwent secondary intraocular lens implantation. Data on 9 eyes are plotted. All points below the line represent improvement in visual acuity

"Rayner PYO" lenses, and two "Jacobi" lenses. The remaining eye was implanted with a "Boberg-Ans" iris-clip lens. 


\section{Results}

Best-corrected preoperative and postoperative visual acuities are given in Table I and Figure 2. Best-corrected postoperative acuity was within 1 Snellen line of bestcorrected preoperative acuity or better in $83 \%$ of the cases. Visual acuity deteriorated by more than 2 Snellen lines in 13 cases. The reasons for visual deterioration are given in Table III.

The visual acuities of the contralateral eyes (65 eyes as 7 patients received bilateral intraocular lenses) are given in Table II. Seventy-two per cent contralateral eyes had a best-corrected visual acuity of $6 / 12$ or better. Twenty-eight per cent of the contralateral eyes were phakic and normal, $34 \%$ were

Table II Visual acuities with secondary implantation

\begin{tabular}{|c|c|c|c|}
\hline & \multicolumn{3}{|c|}{ Best-corrected visual acuity, \% } \\
\hline & \multicolumn{3}{|c|}{$\begin{array}{c}\text { Preoperative Postoperative Contralatera } \\
\text { Eye }\end{array}$} \\
\hline $6 / 6-6 / 9$ & 72 & 55 & 57 \\
\hline $6 / 12-6 / 18$ & 21 & 30 & 30 \\
\hline $6 / 24-6 / 36$ & 6 & 7 & 6 \\
\hline $6 / 60-\mathrm{CF}$ & 1 & 7 & 5 \\
\hline$<\mathrm{CF}$ & 0 & 1 & 2 \\
\hline
\end{tabular}

cataractous, $4 \%$ were aphakic and $34 \%$ were pseudophakic.

The incidence of complications is shown in Table IV. Vitreous loss necessitating anterior vitrectomy was the only immediate surgical complication occurring in three cases. Postoperative complications have been divided into those considered to be major or minor; postoperative astigmatism is considered separately.

\section{Major complications:}

One of the cases of vitreous loss had a persistently shallow anterior chamber

Table IV Incidence of complications*

\begin{tabular}{|c|c|}
\hline Major: 13 cases $(16.5 \%)$ & $\begin{array}{l}\text { Minor: } 13 \text { cases } \\
(16.5 \%)\end{array}$ \\
\hline $\begin{array}{l}\text { Vitreous loss: } 3 \\
\text { Retinal detachment: } 1 \\
\text { Corneal decompensation: } \\
\text { Macular oedema: } 1 \\
\text { Tilted IOL with endothelia } \\
\text { touch: } 1 \\
\text { Displaced IOL: } 1 \\
\text { Incorrect power IOL: } 3\end{array}$ & $\begin{array}{l}\text { Secondary OAG: } 3 \\
\text { Hypopyon: } 3 \\
\text { 3 Hyphaema: } 1 \\
\text { Iris bombé: } 1 \\
\text { Repositioning of } \\
\text { IOL: } 1 \\
\text { PC opacification: } 2 \\
\text { Wound leak: } 1 \\
\text { Vitreous to section: } 1\end{array}$ \\
\hline
\end{tabular}

Table III Reasons for two or more Snellen Line decrease in best corrected visual acuity following secondary implantation

\begin{tabular}{lccl}
\hline & \multicolumn{3}{c}{ Visual acuities* } \\
\cline { 2 - 4 } Patient & Preoperative & Postoperative & Visual acuity* \\
\hline 1 & $6 / 9$ & $\mathrm{CF}$ & Tilted IOL with corneal touch \\
2 & $6 / 6$ & $6 / 18$ & Worsening of SMD \\
3 & $6 / 6$ & $6 / 24$ & Unknown \\
4 & $6 / 60$ & $\mathrm{CF}$ & Corneal decompensation \\
5 & $6 / 9$ & $6 / 18$ & Worsening of diabetic maculopathy \\
6 & $6 / 12$ & $\mathrm{CF}$ & Senile macular hole \\
7 & $6 / 6$ & $\mathrm{NPL}$ & Total retinal detachment \\
8 & $6 / 6$ & $6 / 24$ & PC opacification \\
9 & $6 / 6$ & $6 / 18$ & PCopacification \\
10 & $6 / 9$ & $\mathrm{CF}$ & Corneal decompensation \\
11 & $6 / 9$ & $6 / 18$ & Macular oedema \\
12 & $6 / 9$ & $6 / 24$ & Displaced IOL \\
13 & $6 / 9$ & $\mathrm{CF}$ & Corneal decompensation \\
\hline
\end{tabular}

${ }^{*} \mathrm{CF}$ - Counting fingers; NPL - No perception of light

$\ddagger I O L$ - Intraocular lens; SMD - Senile macular degeneration; PC - Posterior capsule 
postoperatively necessitating removal of the implant with a further anterior vitrectomy. This eye suffered a retinal detachment 6 weeks postoperatively, which ultimately resulted in a blind eye. Three eyes developed corneal decompensation. Persistent postoperative macular oedema developed only in one eye. One anterior chamber intraocular lens was found to be tilted postoperatively resulting in endothelial touch. This could not be repositioned successfully and was removed. One posterior chamber intraocular lens was found to be displaced postoperatively resulting in persistent monocular diplopia. Attempted repositioning proved to be unsuccessful. Three eyes received intraocular lenses of an inappropriate power resulting in marked anisometropia. Two of these cases were due to an error of judgement on the part of the surgeon. In the other case the intraocular lens was found to have been incorrectly packaged.

\section{Minor complications:}

There were three cases of secondary openangle glaucoma successfully controlled on topical B-blockers. There were three cases of

Table V Data on eyes with postoperative astigmatic error $>3.00$ dioptres

\begin{tabular}{|c|c|c|c|}
\hline Patient & $\begin{array}{c}\text { Preoperative } \\
\text { Cylinder }\end{array}$ & $\begin{array}{l}\text { Postoperative } \\
\text { Cylinder }\end{array}$ & Section: * \\
\hline 1 & $+3.50 \times 130$ & $+3.25 \times 145$ & superior \\
\hline 2 & Plano & $+5.00 \times 145$ & superior \\
\hline 3 & Unknown & $+4.00 \times 180$ & temporal \\
\hline 4 & Unknown & $+3.25 \times 115$ & temporal \\
\hline 5 & Unknown & $+3.50 \times 180$ & temporal \\
\hline 6 & Unknown & $+4.00 \times 105$ & temporal \\
\hline 7 & Unknown & $+4.50 \times 5$ & temporal \\
\hline 8 & $+3.25 \times 5$ & $+3.25 \times 15$ & temporal \\
\hline 9 & Unknown & $+4.00 \times 10$ & temporal \\
\hline 10 & $+1.25 \times 180$ & $+5.00 \times 20$ & superior \\
\hline 11 & $+4.00 \times 140$ & $+6.00 \times 175$ & superior \\
\hline 12 & $+0.50 \times 90$ & $+3.50 \times 90$ & temporal \\
\hline 13 & $+3.50 \times 165$ & $+4.50 \times 10$ & superior \\
\hline 14 & $+2.00 \times 10$ & $+4.50 \times 165$ & superior \\
\hline 15 & $+1.50 \times 45$ & $+3.50 \times 60$ & temporal \\
\hline 16 & $+2.25 \times 160$ & $+4.5 \times 180$ & temporal \\
\hline 17 & Unknown & $+3.25 \times 110$ & temporal \\
\hline
\end{tabular}

*Site of corneal incision postoperative sterile hypopyon which resolved on topical steroids alone. One postoperative hyphaema occurred which resolved spontaneously. One case of iris bombé occured due to blockage of the peripheral iridectomy by vitreous. This resolved after a laser iridotomy was performed. Two cases of posterior capsular opacification have occurred. These are awaiting laser capsulotomy. One wound leak occurred which resolved without sequelae. One case of pupillary distortion with a strand of vitreous to the wound occurred with no other sequelae. One intraocular lens was incorrectly positioned and successfully readjusted.

\section{Astigmatism:}

Seventeen eyes $(21 \%)$ had a postoperative astigmatic error greater than $3.00 \mathrm{D}$ with all sutures removed. Table $\mathrm{V}$ documents these cases and shows the site of corneal incision. Unfortunately, in seven of these cases no record of the preoperative astigmatic error was available.

Specular microscopy ws performed on 28 eyes preoperatively but only 14 of these eyes could be subjected to postoperative specular microscopy. The time interval between surgery and postoperative specular microscopy ranged from 6 to 36 months with an average of 14 months. The endothelial cell loss ranged from 2 to $30 \%$ with a mean of $15.6 \%$.

Thirty-seven eyes underwent preoperative biometry. In these the postoperative spherical equivalent range was $+2.50 \mathrm{D}$ to $-4.00 \mathrm{D}$ with a mean of $1.23 \mathrm{D}$. Forty-two eyes were implanted without preoperative biometry. In these the postoperative spherical equivalent range was $+7.25 \mathrm{D}$ to $-5.25 \mathrm{D}$ with a mean of $1.90 \mathrm{D}$.

\section{Discussion \\ We have been impressed by the overall improvement in visual function which secondary intraocular lens implantation affords. In a retrospective study, however, the only available measure of success is post- operative visual acuity and indeed this is the only criterion which is included in most publications on this topic. In this respect our}


results are not as good as those which have previously been published. The latter, however, tend to be single or double surgeon series whereas our'study concerns a large number of surgeons in training. It is, therefore, important to attempt to meet strict criteria in selecting patients for this procedure which can only be achieved by performing a number of investigations.

Much useful information can be gained by a full clinical examination. Aphakic glaucoma is a contraindication particularly if the drainage angle has been compromised by previous cataract surgery and where implantation of an angle-supported lens is contemplated. Gonioscopy, therefore, is mandatory. A single site of peripheral anterior synechiae, particularly to the primary wound, may not exclude surgery but may necessitate the use of a temporal incision in the secondary procedure.

Of major importance is the presence of vitreous in the anterior chamber. ${ }^{(8)}$ In our series this was considered a strict contraindication and probably accounts for our relatively low incidence of retinal complications, especially of cystoid macular oedema (CMO). Kraff et al. ${ }^{(3)}$ found that $16 \%$ of eyes with a ruptured anterior hyaloid face lost vitreous at the secondary procedure.

Even when such a complication is anticipated and an elective anterior vitrectomy performed, Wong et al. ${ }^{(8)}$ found a $28 \%$ incidence of retinal complications. It has also been shown that fluorescein angiography, by establishing the presence or absence of subclinical CMO, may help to identify the patient at risk, particularly those in whom there is only a small area of vitreous herniation. It also seems that a primary to secondary procedure interval of greater than one year reduces the risk of $\mathrm{CMO}^{(9)}$, which applied to most of our patients.

Although most authors advocate the use of specular microscopy, only Kraff reported the degree of endothelial cell loss following secondary implantation showing a $9.4 \%$ loss at 3 months. Our demonstration of a mean cell loss of $15.6 \%$ indicates that for many patients in whom secondary intraocular lens implantation is contemplated, especially in the elderly, there is a significant risk of further compromise of the corneal endothelium. Specular microscopy should therefore be considered in all patients. This investigation was not performed in the 3 patients whose corneas decompensated as a result of surgery and this event might therefore have been avoided.

Our results also show that accurate preoperative refraction, keratometry and biometry are essential. The overall impression gained is that corneal astigmatism, present as a result of the primary procedure, is liable to be made worse by a secondary procedure without any significant change in the axis of the cylinder. This was true even in those cases where a temporal corneal incision was used. Nevertheless, a secondary procedure does provide an opportunity to correct any marked astigmatism already present. The temporal incision described by Masket ${ }^{(10)}$ as a means of reducing against-the-rule astigmatism was through a scleral pocket incision whereas all surgeons in our series used a corneal incision. In either case it would seem likely that an incision made through undisturbed tissue would yield a more predictable result. A careful choice of the power of intraocular lens to be implanted cannot be over-emphasised, taking into account the corrected visual acuity of the other eye and its status i.e. phakic, aphakic or pseudophakic. It has been shown by Summers and Lindstrom ${ }^{(5)}$ that preoperative biometry is much more accurate than relying on the refraction method. Nevertheless, in our series a large postoperative error was found in 3 cases. In one case the error occurred because the intraocular lens had been incorrectly packaged by the manufacturer, and in the other two cases because of an error of judgement on the part of the surgeon. Although we were obliged to exclude from this series some patients where primary implantation failed, we feel that this is an important group worthy of further study. This problem is particularly likely to occur in a training centre where the relatively inexperienced surgeon may, encounter operative problems such as miosis or a poorly maintained anterior chamber preventing safe implantation. 
Not infrequently, we have found that it is the patient who is the first to raise the possibility of secondary implantation. This is particularly likely where the other eye has already undergone successsful cataract surgery with lens implantation. It is this kind of pressure generated by the patient which emphasises the need to consider carefully the suitability of the eye rather than the patient for secondary implantation. Ideally, this assessment should include careful slit-lamp biomicroscopy paying particular attention to the presence of peripheral anterior synechiae and the condition of the anterior hyaloid face. The retinal periphery and the macula should be examined carefully particularly where there is a small degree of vitreous herniation into the anterior chamber. The corneal endothelium should be examined by specular microscopy. Refraction, keratometry and biometry should be performed. A visco-elastic substance should be used during surgery which can be performed under either local or general anaesthesia. One further consideration is the age of the patient. The demonstration by Graham et al. ${ }^{(11)}$ of a low success rate for the use of daily wear and extended wear contact lenses for aphakia in the over 70 s suggests this group should be given full consideration for a secondary procedure.

The development of epikeratophakia promises a further alternative method of managing aphakia particularly where the patient is unsuitable for secondary implantation. ${ }^{(12,13)}$ In the meantime secondary implantation accounted for $3 \%$ of all implants used in the Manchester Royal Eye Hospital in 1987. We anticipate that the incidence of secondary implantation will peak within the next few years and then fall in line with the numbers of aphakic patients.

Despite the fact that $14 \%$ of our patients suffered a significant and irreversible loss of visual acuity and despite the significant risk of complications, we have been impressed by the dramatic improvement in the visual status of a large majority of the patients studied. With improved selection and preoperative assessment, we feel confident that in the hands of an experienced surgeon, secondary lens implantation has an important part to play in the rehabilitation of aphakic patients.

\section{References}

${ }^{1}$ Mazzocco TR, Kratz RP, Davidson B, Colvard DM. Secondary posterior chamber intraocular lens implants. Am Intraocul Implants Soc J 1981, 7: 341-3.

${ }^{2}$ Lindstrom RL, Harris WS, Lyle WA. Secondary and exchange posterior chamber lens implantation. Am Intraocul Implant Soc J 1982, 8: 353-6.

${ }^{3}$ Kraff MC, Sanders DR, Lieberman HL, Kraff H. Secondary intraocular lens implantation. Ophthalmology 1983, 90: 324-6.

${ }^{4}$ Shammas HJF and Milkie CF. Secondary implantation of anterior chamber lenses. $A m$ Intraocul Implant Soc J 1983, 9: 313-6.

${ }^{5}$ Summers CG and Lindstrom RL. Secondary IOL power calculations: A comparison of regression formula and refraction method in accurate prediction of emmetropia. $\mathrm{Am}$ Intraocul Implant Soc J 1984, 10: 448-51.

${ }^{6}$ Binder PS: Secondary intraocular lens implantation during of after corneal transplantation. Am J Ophthalmol 1985, 99: 515-20.

${ }^{7}$ Kraff MC, Lieberman HL, Sanders DR: Secondary intraocular lens implantation: rigid/semi-rigid versus flexible lenses. $J$ Cataract Refract Surg 1987, 13: 21-6.

${ }^{8}$ Wong SK, Koch DD, Emery JM: Secondary intraocular lens implantation. $J$ Cataract Refract Surg 1987, 13: 17-20.

' Shammas HJF and Milkie CF: Cystoid macular oedema following secondary lens implantation. Am Intraocul Implant Soc J 1981, 7: 40-2.

${ }^{10}$ Masket S: Temporal incision for astigmatic control in secondary implantation. $J$ Cataract Refract Surg 1986, 12: 179-81.

${ }^{11}$ Graham CM, Dart JKG, Wilson-Holt NW, Buckley RJ: Prospects for contact lens wear in aphakia. Eye 1988, 2: 48-55.

${ }^{12}$ Rostron CK: Epikeratophakia: clinical results and experimental development. Eye 1988, 2: $56-62$.

${ }^{13}$ Durrie DS, Habrich DL, Dietze TR: Secondary intraocular lens implantation vs epikeratophakia for the treatment of aphakia. Am J Ophthalmol 1987, 103: 384-91. 